\title{
Neonicotinoids in U.S. Maize: Insecticide Substitution Effects and Environmental Risk
}

\author{
Edward D. Perry and GianCarlo Moschini \\ Working Paper 19-WP 590 \\ May 2019
Center for Agricultural and Rural Development
lowa State University
Ames, lowa 50011-1070
www.card.iastate.edu

Edward D. Perry (edperry@ksu.edu) is Assistant Professor, Department of Agricultural Economics, Kansas State University, Manhattan, KS 66506.

GianCarlo Moschini (moschini@iastate.edu) is Professor and Pioneer Chair in Science and Technology Policy, Department of Economics and Center for Agricultural and Rural Development, lowa State University, Ames, IA 50011.

This publication is available online on the CARD website: www.card.iastate.edu. Permission is granted to reproduce this information with appropriate attribution to the author and the Center for Agricultural and Rural Development, lowa State University, Ames, lowa 50011-1070.

lowa State University does not discriminate on the basis of race, color, age, ethnicity, religion, national origin, pregnancy, sexual orientation, gender identity, genetic information, sex, marital status, disability, or status as a U.S. veteran. Inquiries can be directed to the Interim Assistant Director of Equal Opportunity and Compliance, 3280 Beardshear Hall, (515) 294-7612. 


\title{
Neonicotinoids in U.S. maize: Insecticide substitution effects and environmental risk
}

\author{
Edward D. Perry and GianCarlo Moschini *
}

\begin{abstract}
This study exploits a novel dataset containing more than 89,000 farm-level surveys over a 17-year period to investigate how neonicotinoid seed treatments in maize, now ubiquitous, have affected the use of other insecticides. Neonicotinoid insecticides are the most used class of insecticides in the world, but they are controversial because of their high toxicity to honeybees. In the United States, maize production accounts for the majority of neonicotinoid use, mostly as seed treatments. We find that neonicotinoids substituted for other major insecticides: plots planted with neonicotinoidtreated seeds were $52 \%$ and $47 \%$ less likely to be treated with a pyrethroid and organophosphate insecticide, respectively. Although honeybees have been put at greater risk by neonicotinoids, the changed pattern of pest control instruments has reduced toxicity risk for mammals, birds, and fish. We also find that adoption of genetically engineered insect-resistant maize varieties significantly reduced the use of organophosphate and pyrethroid insecticides, thereby reducing toxicity exposure to all examined taxa. Policies aimed at restricting neonicotinoid use may need to account for undesirable unintended consequences.
\end{abstract}

Key Words: environmental risk, genetically engineered maize, insect control options, insecticides, neonicotinoids, pesticide ban, substitution effects, unintended consequences

JEL codes: Q1, Q5

* Edward D. Perry (edperry@ksu.edu) is Assistant Professor in the Department of Agricultural Economics, Kansas State University, Manhattan, KS 66506. GianCarlo Moschini (moschini@,iastate.edu) is Professor and Pioneer Chair in Science and Technology Policy, Department of Economics and Center for Agricultural and Rural Development, Iowa State University, Ames, IA 50011.

This research was supported by the National Institute of Food and Agriculture, U.S. Department of Agriculture, grant No. 2019-67023-29420. 


\section{Introduction}

Neonicotinoid insecticides have emerged as an integral part of agricultural production. Since their commercial introduction in 1991, they have become the most used class of insecticides in the world, totaling more than $\$ 3$ billion in sales in 2012 (Jeschke et al. 2011; Bass et al. 2015). In the United States, where most applications take the form of seed treatments, neonicotinoids are now applied on more than 50\% of soybean acres (Hurley and Mitchell 2017) and more than 90\% of maize acres, with maize alone accounting for over 60\% of neonicotinoid use in U.S. agriculture (USGS 2018). Despite their commercial success, neonicotinoids have come under intense scrutiny for their possible link to declining honeybee (Apis mellifera) populations. This hypothesis emerged subsequent to the development of Colony Collapse Disorder (CCD), a phenomenon first described in 2006-07 when abnormally high bee losses were reported (Henry et al. 2012). In response to mounting evidence of neonicotinoids' potential role in CCD, the European Union (EU) banned neonicotinoids in 2013 (Stokstad 2013), and in the United States there have been recent calls to restrict their use (Goulson 2018).

The policy questions raised by neonicotinoids are not new in the context of pesticides (Feder and Regev 1975; Zilberman et al. 1991; Hubbell, Marra, and Carlson 2000). Chemical inputs such as insecticides and herbicides are essential to modern commercial agriculture, and have been credited with contributing substantially to agricultural productivity increases in both developed and developing countries. But pesticides are controversial because of potentially adverse health and environmental effects (Wilson and Tisdell 2001; Lai 2017). Most countries have developed elaborate regulations to address these external effects, which include risk assessments prior to approval (registration), and monitoring with ex post command and control mechanisms such as use restrictions and bans (deregistration) (Zilberman and Millock 1997; Sexton, Lei, and Zilberman 2007). The pervasive market failures that are involved suggest that existing outcomes represent second-best solutions, with the real possibility of unintended effects. A major issue has to do with substitutability between insect control options. A specific product ban may limit a specific risk, ceteris paribus, but other risks may materialize as farmers choose alternative pest control strategies. Indeed, the risk-only approach that underpins the U.S. regulatory framework makes it difficult to account for substitutability and general equilibrium effects (Osteen and Fernandez-Cornejo 2013). In the context of neonicotinoids, if a ban were implemented in the United States, farmers would likely turn to other currently available insect control options. From a risk perspective, therefore, the policy-relevant question is whether the post-ban 
situation would result in insecticide usage patterns that are better for the environment and/or human health.

In this paper, we provide novel empirical evidence on several key impacts associated with the widespread adoption of neonicotinoid seed treatments (NeoST) in U.S. maize. The main goals of this analysis are to identify the degree of substitution between NeoSTs and conventional insecticides, to determine what these substitution patterns imply in terms of environmental impact, and to predict farmer adjustments in response to a hypothetical neonicotinoid ban in U.S. maize. Concomitantly, we also aim to identify and disentangle the separate insecticide use impacts of NeoSTs from those attributable to the adoption of genetically engineered (GE) varieties that embed traits based on Bacillus thuringiensis $(\mathrm{Bt})$ genes.

Economic analysis has shown that farmers ultimately care about the impact of pest damage on production. Existing economic models emphasize the damage-control input nature of pesticides (Lichtenberg and Zilberman 1986; Oude Lansink and Carpentier 2001; Wechsler and Smith 2018), with farmers choosing preventative and/or responsive pesticide applications to maximize expected profits, subject to the constraints imposed by available options. Over the past two decades, there have been radical changes in the set of available insect control options. GE insect-resistant varieties were introduced in the late 1990s and early 2000s, and NeoST maize was introduced in 2004. Most farmers now use these newer options for insect control, relying less on conventional insecticides. In 2010, for example, just over $10 \%$ of maize acres were treated with conventional insecticides, a more than $75 \%$ decrease from its peak at 45\% in the mid-1980s (Osteen and Fernandez-Cornejo 2013; Coupe and Capel 2016).

Neonicotinoids can persist in the environment, accumulate in soils, leach into waterways, and they pose a threat to a number of other non-target species, especially pollinators and soil and aquatic invertebrates (Goulson 2013). But the main available alternative pest control optionsorganophosphate and pyrethroid insecticides (Furlan and Kreutzweiser 2015)—have limitations of their own. Organophosphates are widely considered more dangerous for applicators and mammals than neonicotinoids (Hurley and Mitchell 2017), and pyrethroids are highly toxic to aquatic life and often as toxic to non-target insects (Douglas and Tooker 2016). Empirical evidence of substitution into these insecticides has recently been documented in the EU, where it has been found that the EU neonicotinoid ban has led to increases in the use of alternative soil and foliar applied insecticides in 
both maize (Kathage et al. 2018) and oilseed rape production (Kathage et al. 2018; Scott and Bilsborrow 2019; Dewar 2017).

The availability of detailed data has been a limiting factor to existing research on the impacts of actual neonicotinoid use in U.S. agriculture (Douglas and Tooker 2015). The Pesticide National Synthesis Project maintained by the U.S. Geological Survey (USGS) provides the most comprehensive source of pesticide use data in the United States, including NeoSTs (Thelin and Stone 2013). However, these data are only available at an aggregated (regional or national) level. Thus, while they can be used to construct some of the environmental impact metrics that we report below, they cannot be used to reliably characterize the impact of NeoSTs on the use of alternative insecticides, nor their impact on toxicity exposure to various species. For this purpose, farm-level data on a large scale is essential.

To address these shortcomings, this study uses data on insecticide applications from more than 89,000 U.S. farm-level surveys, encompassing 182,307 distinct sets of pesticide-related choices during the 1998-2014 period. The thrust of our analysis consists of estimating the impact of NeoST adoption on two different measures of insecticide use intensity. Importantly, all estimated models include control variables for the separate effects due to the introduction and diffusion of GE insect-resistant varieties that embed Bt traits.

Using linear probability models, we first estimate the impact of NeoST adoption on the likelihood of using each of five major insecticide subgroups: organophosphates, pyrethroids, carbamates, phenylpyrazoles, and category I insecticides. ${ }^{1}$ We find that NeoST maize adopters are $52 \%$ less likely to use a pyrethroid, $47 \%$ less likely to use an organophosphate, and $46 \%$ less like to use a category I insecticide. These impacts are robust to the inclusion of Bt trait controls, which are themselves found to reduce insecticide use (albeit to a lesser degree than NeoSTs).

These insecticide regression models are informative about the substitution effects brought about by NeoST adoption, but do not reveal the direction or magnitude of their net environmental impact. Individual insecticides have widely different environmental impacts which depend, inter alia, on the species-specific toxicity of the active ingredient and its application rate. To address this pesticideheterogeneity issue, we adopt a procedure consistent with risk assessment methods used by the EPA and several previous related studies (EPA undated; Nelson and Bullock 2003; Nowell et al. 2014; Kniss

\footnotetext{
${ }^{1}$ Category I insecticides are those deemed by the U.S. Environmental Protection Agency (EPA) to be extremely
} hazardous to humans. 
2017). Specifically, for each observed insecticide application we compute a risk quotient: the ratio of the insecticide's observed application rate to its toxicity rating. For each plot (our unit of observation), we then compute a hazard quotient: the sum of risk quotients for all applied insecticides on that plot, including the risk quotient for a NeoST (if adopted). Using these plot-specific hazard quotients as the dependent variable of interest, we then estimate NeoST impact regressions for four different species groups: mammals, birds, fish, and honeybees. In short, we do find that plots planted with NeoST maize pose higher toxicity risk for bees on average, as expected, but we also find robust evidence that such plots pose significantly lower toxicity risk for mammals and fish.

The strength of this paper lies in its empirical contribution to the literature, which is predicated on a large and representative sample of actual farmers' choices. As with any observation-based empirical study, however, in estimating the impacts of NeoST adoption on insecticide use we face the issue of selection bias and unobserved confounders. In our setting, we must address the fact that farmers choose whether or not to adopt to NeoST maize. To the extent that some farmers adopt NeoST maize for unobserved reasons related to their other insect control choices, then the estimated treatment effects may be biased. To control for unobserved confounders, we include farmer fixed effects, which eliminate bias that would result from unobserved confounding time-invariant farm-level factors such as education, risk aversion, and average farm-specific differences in insect pressure. We also include year fixed effects, which control for factors such as output prices, insecticide prices, and nationwide year-to-year variation in insect pressure and insect resistance. Perhaps the most important remaining potential unobserved confounder is expected pest pressure that varies over time and space. We note, however, that farmers who encounter high pest pressure will be more likely to use all forms of insect control. The estimated NeoST impact coefficient will soak up some of this effect and, therefore, be biased towards indicating complementarity, rather than substitutability, with insecticide use. We thus view our results as conservative estimates of the degree to which NeoSTs substitute for insecticides.

The analysis and findings presented here make several important contributions to the extant literature. With the exception of the limited case-study-based findings following the EU neonicotinoid ban (Kathage et al. 2018; Scott and Bilsborrow 2019; Dewar 2017), there are no large scale empirical studies that document and estimate the impacts of widespread neonicotinoid use. In addition, there is no existing work that uses farm-level data to estimate and disentangle the impacts of both NeoST and GE trait adoption on the likelihood of using specific insecticide groups, nor do any previous studies estimate their impacts on toxicity risk for different species. Whereas we find a significant role for GE 
traits, a result consistent with previous studies that do not control for neonicotinoids (Perry et al. 2016; Klümper and Qaim 2014), our findings suggest that NeoST adoption has been more instrumental than Bt trait adoption in contributing to the large observed reduction in conventional insecticide use. Perhaps most importantly, our results contribute important information to the intensifying policy debate on neonicotinoid restrictions in the United States. A major implication of our findings is that policymakers should be aware of the potential for undesirable unintended consequences from neonicotinoid restrictions, particularly the potential for substitution into some of the more hazardous insecticide compounds such as organophosphates and category I insecticides. ${ }^{2}$

\section{Background and Data}

Neonicotinoids are a class of systemic insecticides that act on the central nervous system in insects. Their use has grown rapidly since their commercial introduction in 1991. By 2014, they comprised more than $25 \%$ of the global insecticide market, with registered uses for over 140 crops in 120 countries (Jeschke et al. 2011; Bass et al. 2015). Neonicotinoids can be applied through spraying, soil treatment, or in the form of seed treatments. For the main row crops in the United States, essentially all neonicotinoid applications take the form of seed treatments (Douglas and Tooker 2015), with three neonicotinoid compounds comprising the vast majority of treatments: imidacloprid, thiamethoxam, and clothianidin.

NeoSTs' appeal to farmers is reflected in the fact that, ultimately, they improve farm-level productivity. Field-based experiments have demonstrated positive yield effects of neonicotinoids seed treatments (NeoSTs) on a range of major field crops, although the benefits vary significantly by crop and the degree of pest pressure. For example, in maize production, multiple studies find positive yield benefits, but these benefits diminish or completely disappear in the absence of insect attacks (Wilde et al. 2004; Wilde et al. 2007; Alford and Krupke 2018).

The fundamental driver of the magnitude of substitutability between NeoST and insecticides is the degree to which they efficiently target similar pests. Previous literature has found that neonicotinoids act on a wide range of economically significant pests (Jeschke et al. 2011). At suitable doses, NeoSTs are moderately to highly effective in treating various species of rootworm, the most problematic pest

${ }^{2}$ Consider that in the United States there are as many as 300,000 pesticide poisonings per year (Pimentel 2005). Between 2005 and 2009, pyrethroids and organophosphates were the first- and the third-most reported insecticides in poisoning cases (Roberts and Reigart 2013). Neonicotinoids were not among the top ten. 
in U.S. maize (Cox et al. 2007; Alford and Krupke 2018). Thus, farmers seeking moderate control of rootworms, particularly farmers who opted not to plant RW varieties (a large fraction of planted maize), may have opted for NeoST seed instead of using a preventative soil-applied insecticide such as a pyrethroid or organophosphate (Furlan and Kreutzweiser 2015). NeoSTs are also highly effective in treating a wide range of secondary pests, including cutworm, wireworm, and maggots (Wilde et al. 2007). Although secondary pests are often sporadic, the extensive survey data used in this study indicate that such pests constituted a significant fraction of the pests targeted by U.S. maize farmers (Table A6 in the Appendix provides some evidence). Thus, even before NeoSTs were commercially available, farmers often applied insecticides prophylactically with respect to secondary pests. For these farmers, the advent of NeoSTs may have simply provided a more convenient method for treating secondary pests.

\subsection{Data Sources}

Data on insecticide use and GE trait adoption come from AgroTrak, a proprietary dataset assembled by the private market research company Kynetec USA, Inc. Each year, Kynetec conducts surveys of randomly sampled farmers in the United States. The sampling procedure is designed to be representative at the crop reporting district (CRD) level and extends to all 48 contiguous states across 296 CRDs. The average number of maize farms surveyed over this period is about 5,242 per year. For each farmer, we observe which GE traits were used (if any), the insecticide products used (if any), and for each of those products we observe: quantity used, area treated, maize acres planted, and price paid. Many farmers are surveyed multiple years, and within a given year we observe multiple distinct decisions per farmer, each applying to a separate plot of planted maize. It is also worth noting that the Kynetec pesticide data are used by the USGS to produce their comprehensive regional and national statistics on pesticide use in the United States. However, USGS does not provide access to the raw plot-specific farm-level data, as utilized in this study. Further details concerning the AgroTrak data are provided in the Appendix.

The risk and hazard quotient measures used throughout this study require acute LD50 toxicity values, which, for a given insecticide, is an estimate of the dose that is lethal to $50 \%$ of a tested population (e.g., rats). Data on LD50 values were assembled from several different sources. The honeybee values are from Sanchez-Bayo and Goka (2014). The bird LD50 values are the median LD50 values reported in Mineau et al (2001). For the fish LC50 values, we use the median reported values from Nowell et 
al. (2014). For a small number of active ingredients, these papers do not report LD50 values, in which case the data were obtained from other standard sources such as the Toxnet HSDB database and EXTOXNET. The rat LD50 values are the median of values reported in the Toxnet HSDB database. The actual LD50 values used for the computation of the hazard quotients and for the estimation of the impact regression models are reported in the Appendix (Table A3).

\section{Insect Control in U.S. Maize}

Maize insect control options currently take three main forms: GE insect-resistant varieties that embed Bt traits; foliar or soil applied insecticides; and, seed dressed (treated) insecticides. Pyrethroid and organophosphate insecticides account for the vast majority of foliar and soil applied insecticides in terms of volume and acres, and neonicotinoids account for virtually all seed treated insecticides. Together, these three insecticide groups comprised nearly $99 \%$ of the maize area treated with insecticides in 2014.

\subsection{Adoption Trends in Insect Control Practices}

Figure 1 illustrates the evolution of insect control practices in U.S. maize over the period 1998-2014. During this timeframe, the share of Bt maize rose significantly, from about $10 \%$ to over $80 \%$. The most common GE trait conveys resistance to the European corn borer (CB), Ostrinia nubilalis. GE traits conferring resistance to the western corn rootworm (RW), Diabrotica virgifera virgifera, were introduced in 2003 and were typically stacked in varieties that already embedded CB resistance (often with herbicide tolerance traits as well) (Perry et al. 2016). Neonicotinoid seed treatments were introduced in 2004. Their diffusion was even faster, and eventually more widespread, than Bt varieties. By 2014, the share of planted maize treated with neonicotinoids exceeded 95\%. Concomitantly, the share of planted acres treated with foliar or soil-applied insecticides fell from a high of 33\% in 2003 to a low of $10 \%$ in 2010 (and then up again to 16\% in 2014). Maize acreage treated with pyrethroid and organophosphate insecticides fell from highs of $21 \%$ and $17 \%$ to $13 \%$ and $4 \%$ in 2014 , respectively. The fall in these shares was sharpest from 2004 onward, suggesting that neonicotinoids served as major substitutes. However, the diffusion of CB and RW traits occurred around the same time, and thus could also explain the decline in insecticide use. Hence, in what follows, we will endeavor to disentangle the separate effects of NeoSTs from those of Bt varieties. 


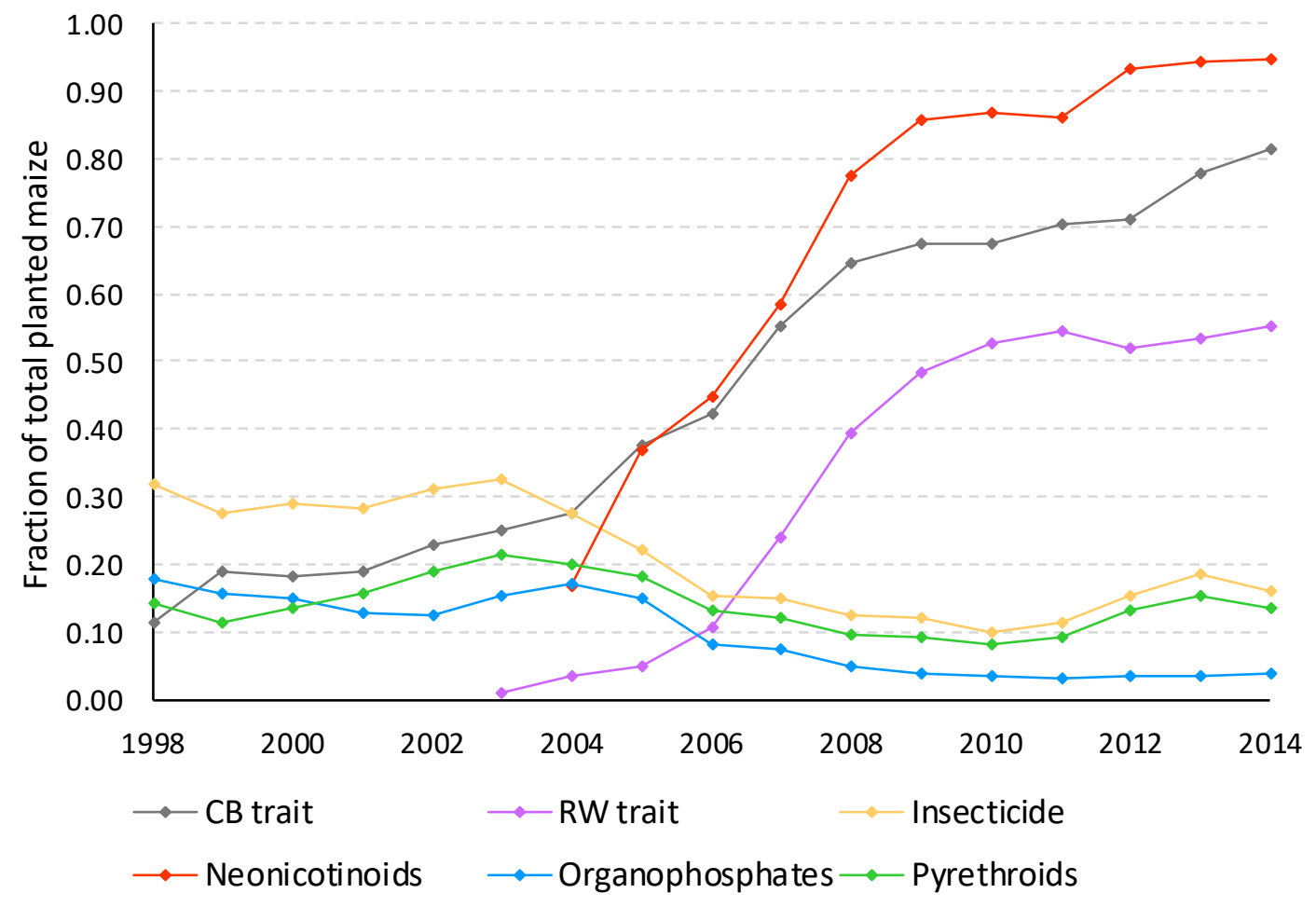

Figure. 1. Adoption rates of major insect control options in U.S. maize, 1998-2014. Lines chart the fraction of U.S. planted acres that embed GE traits for resistance to the European corn borer (CB trait) and corn rootworm (RW trait), and the fraction of U.S. acres with at least one treatment of an insecticide (foliar or soil applied), neonicotinoids, organophosphates, and pyrethroids.

\subsection{Trends in Area Treated by Insecticide Subgroups}

Summarizing changes in insecticide use is made difficult by the fact that, in any given year, more than 30 insecticide chemicals (active ingredients) are applied in maize production. To succinctly characterizes changes in use, we categorize individual chemicals by mode-of-action subgroups, as classified by the Insecticide Resistance Action Committee (Sparks and Nauen 2015). For example, neonicotinoid compounds comprise one mode of action subgroup and, in our sample, includes the active ingredients clothianidin, imidacloprid, and thiamethoxam. We first measure changes in insecticide use over time using the concept of area-treatments (Kniss 2017). This measure is an improvement over quantity applied because of the large differences in application rates between insecticides (see Table A4 for mean application rate by insecticide compound). For each insecticide 
subgroup in each year, the number of area-treatments are obtained by dividing total area treated by total maize planted area:

$$
A T_{g t}=\frac{\text { TotalAreaTreated }_{g t}}{\text { MaizePlantedArea }}
$$

where $g$ denotes an insecticide subgroup and $t$ denotes a year. Intuitively, area-treatments are the number of treatments per field.

Figure 2 reports area-treatments for five insecticide subgroups and one catch-all subgroup termed "other." For each year, the bar on the right depicts NeoST area-treatments and the (stacked) bar on the left depicts area-treatments for the remaining insecticide subgroups. Trends in area-treatments are similar to the adoption rate trends reported in Figure 1. Following their introduction in 2004, neonicotinoids rapidly expanded, reaching 1.1 area-treatments by $2014 .^{3}$ Once again, major declines in insecticide use occurred in the mid-2000s as NeoST adoption ramped up. Combined areatreatments of pyrethroids and organophosphates fell from nearly 0.4 area-treatments to just over 0.1 area treatments in 2010. Some other developments are also worth noting. Phenylpyrazoles, which include the active ingredient fipronil and are even more toxic to bees than NeoSTs, essentially disappeared from use by 2010. Similarly, carbamates, which are considered among the most toxic to mammals and humans, had largely disappeared from use before the emergence of NeoSTs in 2004. By contrast, the use of pyrethroids increased a bit in recent years, possibly due to evolving insect resistance to RW traits (Gassmann et al. 2014).

\footnotetext{
${ }^{3}$ Area-treatments can exceed 1 because more than one neonicotinoid compound can be applied to a seed.
} 


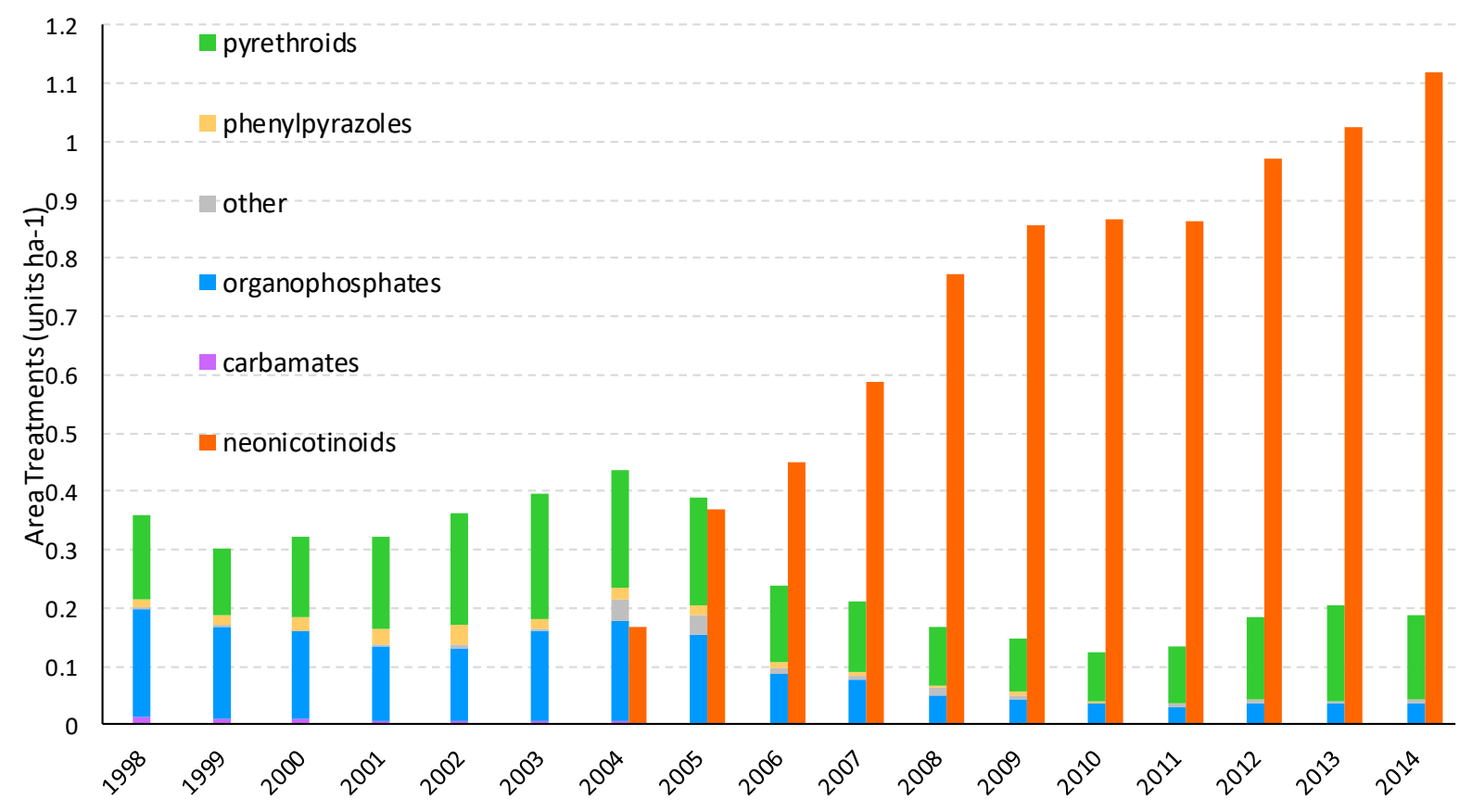

Figure. 2. Insecticide area-treatments in U.S. maize, 1998-2014. Area-treatments represent the average number of insecticide treatments applied on each plot. The contribution of the main insecticide groups is represented by color-coded stacked columns.

\subsection{Toxicity of Applied Insecticides: Hazard Quotients.}

Pesticides are highly heterogeneous in their toxicity to various species. Thus, tracking the total number of treated acres (or quantity), as in Figure 2, provides a poor measure of environmental impact. A more informative way of comparing pesticides is to look at their application rate in combination with their toxicity, as measured by their LD50 rating. For approval by the U.S. Environmental Protection Agency (EPA), pesticides must be tested on a variety of species, including rats, bees, fish, and birds. Table A3 in the Appendix shows that maize insecticides differ considerably in terms of their LD50 rates. NeoSTs typically possess the highest LD50 ratings (a higher rating implies lower toxicity) and are among the least harmful insecticides with respect to rats, fish, and birds; they are, however, the second-most toxic to bees (phenylpyrazoles are the most toxic). Organophosphates, by contrast, are relatively toxic to all groups, particularly rats and birds, and pyrethroids are highly toxic to bees and extremely toxic to fish. To give an example, the organophosphate tebupirimphos has a median rat 
LD50 of $2.4 \mathrm{mg} / \mathrm{kg}$, while the neonicotinoid thiamethoxam has a median rat LD50 of 1,563 mg/kg. Thus, it takes about 650 times more quantity of thiamethoxam to have the same lethal effect.

In addition to the fact that different insecticides possess different toxicity ratings, they also differ considerably in their application rates (Table A4). Returning to the previous example, a typical application of the organophosphate compound tebupirimphos is $0.14 \mathrm{~kg} / \mathrm{ha}$, whereas a typical application of thiamethoxam is $0.015 \mathrm{~kg} / \mathrm{ha}$. Tebupirimphos is therefore both more acutely toxic and applied at higher rates. Thus, a suitable metric to measure environmental risk should account for differences in both application rates and toxicity across insecticides.

Following previous studies in this area, we adopt a risk quotient approach (EPA undated; Nelson and Bullock 2003; Nowell et al. 2014; Kniss 2017). The EPA, in the context of ecological risk assessment, defines the risk quotient $(R Q)$ for a particular chemical as the ratio of exposure to toxicity (EPA, undated). Following Nelson and Bullock (2003) and Kniss (2017) we use quantity applied as our measure of exposure, and the acute LD50 as our measure of toxicity. Although quantity applied is an imperfect measure of toxicity exposure, it is nonetheless an informative metric of insecticide toxicity, particularly when viewed as a first step towards identifying potential tradeoffs between insecticide use patterns. Moreover, the risk quotient approach is superior to approaches that simply use area or total weight as a measure of insecticide use, two measures frequently used in the previous literature (Kniss 2017). Formally, the risk quotient for pesticide $j$ applied to plot $i$ is defined as:

$$
R Q_{i j}=\frac{q_{i j}}{L D 50_{j}}
$$

where $q_{i j}$ is the quantity $\left(\mathrm{mg} \mathrm{ha}^{-1}\right)$ of insecticide $j$ applied to plot $i$, and $L D 50_{j}$ is the LD50 value (for a particular species) of insecticide $j$. The risk quotient can be interpreted as the number of LD50 doses per hectare associated with the observed use of insecticide $j$ on plot $i$. The total toxicity associated with plot $i$ is given by the hazard quotient $(H Q)$, defined as the sum of all insecticide risk quotients on that plot:

$$
H Q_{i}=\sum_{j} R Q_{i j}
$$


To provide a broad perspective, we consider acute LD50 values for four different groups of organisms: mammals (rats), birds, bees, and fish (for fish, we actually use LC50 values). To give an example, if a field was planted with NeoST maize and received a pyrethroid application, the rat hazard quotient for that field would be the sum of the rat risk quotients for the NeoST and pyrethroid applications. The hazard quotient for fields with non-NeoST maize and without any insecticides is zero.

Trends in estimated hazard quotients for U.S. maize are illustrated in Figure 3. Color-coded stacked bars show the contribution of each insecticide subgroup to the overall hazard quotient. These figures demonstrate the stark contrast between area-treatments and toxicity-based indices. Whereas areatreatments surged during the expansion of NeoST maize, three out of four hazard quotients fell dramatically. In mammals, for example, acute toxicity exposure declined by more than $80 \%$, from about 27 units ha ${ }^{-1}$ in 1998 to under 5 units ha ${ }^{-1}$ in 2014. Most of the early decline was due to reductions in the use of high-rate organophosphates like terbufos and phorate. Declining values later in the sample came from reductions in the use of compounds tebupirimphos and chlorpyrifos. Acute toxicity for birds has also decreased considerably, in large part due to the declining use of organophosphates but also from reductions in the use of carbamates. The latter have been used in small quantities in maize production, but are very toxic to birds (and quite toxic to mammals). Risk exposure for fish (panel D in Figure 3) has come primarily from organophosphates and pyrethroids. Falling usage of both of these insecticides led to an overall decline of exposure, with pyrethroids remaining the most significant source of risk, and actually increasing in the final three study years.

For bees (panel $\mathrm{C}$ in Figure 3) the trends are more complex. Prior to the introduction of neonicotinoids, risk exposure was mostly determined by the use of organophosphates, phenylpyrazoles, and pyrethroids. The diffusion of NeoSTs, beginning in 2004, quickly replaced these other insecticides as the largest source of bee risk exposure. In particular, the contribution of phenylpyrazoles and organophosphates declined significantly, with the role of pyrethroids fluctuating over the study period, and emerging as the second-largest source of risk to bees in the last three years of the sample. Overall, acute risk to bees declined initially upon the diffusion of NeoSTs, but increased in the final years of the sample, reaching levels slightly higher than observed levels prior to NeoST commercialization. Much of the increase in later years seems to be due to increasing application rates 
for neonicotinoid seed dressings. Notably, acute risk exposure was actually lowest during the years in which Colony Collapse Disorder emerged.
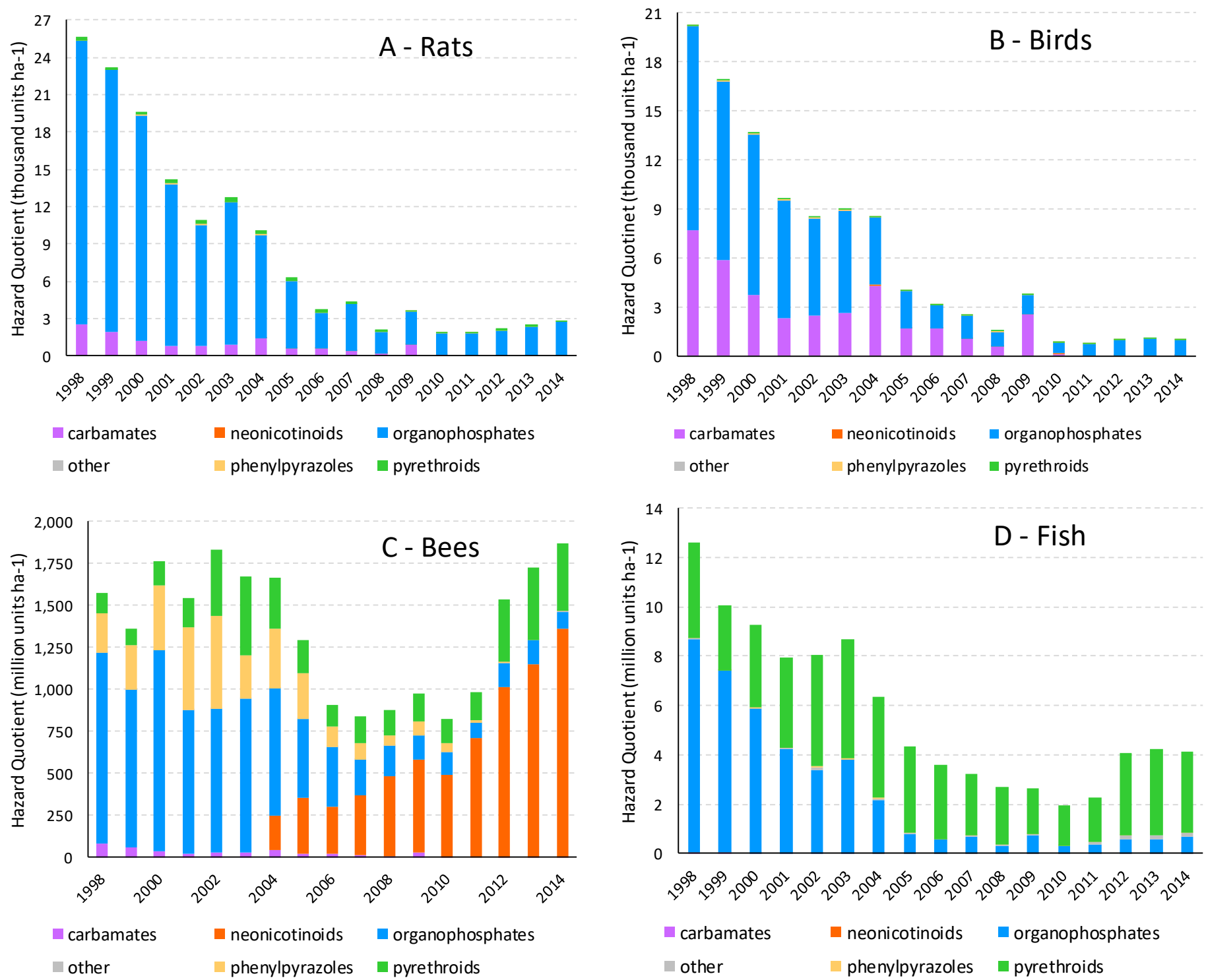

Figure. 3. Exposure to insecticides use in U.S. maize, 1998-2014, measured by hazard quotient for rats (A), birds (B), bees (C), and fish (D). Stacked column report the total number of LD50 units applied per hectare, with colored-coded contribution by main insecticide groups. Scale: thousands of LD50 mg/ kg/ha units (A and B) millions of LC50 $\mu \mathrm{g} / \mathrm{L} / \mathrm{ha}$ units $(\mathrm{C})$ and millions of LD50 $\mu \mathrm{g} / \mathrm{bee} / \mathrm{ha}(\mathrm{D})$. 


\subsection{Differences in Insecticide Use between NeoST and non-NeoST Plots}

The trends and results discussed in the foregoing suggest that the introduction and rapid diffusion of NeoSTs changed the composition of insecticides used in maize production. As previously noted, there are also agronomic reasons to believe that NeoSTs substituted for older insecticides. Specifically, NeoSTs potentially substitute for insecticides that treat corn rootworm and/or secondary pests.

Table 1. GE Trait Adoption, Insecticide Use, and Hazard Quotients

\begin{tabular}{|c|c|c|}
\hline Variable & $\begin{array}{c}\text { non-NeoST } \\
\text { plots }\end{array}$ & NeoST plots \\
\hline $\mathrm{CB}^{\dagger}$ & 0.249 & $0.665^{+}$ \\
\hline $\mathrm{RW}^{\dagger}$ & 0.005 & $0.485^{+}$ \\
\hline Pyrethroid $^{\dagger}$ & 0.159 & $0.113^{*}$ \\
\hline Organophosphate ${ }^{\dagger}$ & 0.145 & $0.043^{*}$ \\
\hline Phenylpyrazole ${ }^{\dagger}$ & 0.016 & $0.003^{*}$ \\
\hline Carbamate $^{\dagger}$ & 0.008 & $0.001 *$ \\
\hline Rat Hazard Quotient ${ }^{\S}$ & 13.068 & $2.84 *$ \\
\hline Fish Hazard Quotient ${ }^{\S}$ & 7.659 & $3.20^{*}$ \\
\hline Bird Hazard Quotient ${ }^{\S}$ & 10.528 & $1.63^{*}$ \\
\hline Bee Hazard Quotient $^{\S}$ & $1,456.10$ & $1,335.05^{*}$ \\
\hline$N$ & 95,124 & 87,183 \\
\hline
\end{tabular}

Note: ${ }^{\dagger}$ The table entries are averages of indicator variables identifying the presence of the respective trait or insecticide (hence, they indicate the fraction of observed plots with variable equal to one).

$\checkmark$ Units: thousands of LD50 mg/kg/ha for rats and birds, millions of LC50 $\mu \mathrm{g} / \mathrm{L} / \mathrm{ha}$ for fish, and millions of LD50 $\mu \mathrm{g} / \mathrm{bee} / \mathrm{ha}$ for bees.

${ }^{+}$Greater than non-NeoST mean at the $1 \%$ level.

* Less than non-NeoST mean at the $1 \%$ level.

Basic summary statistics further indicate that there are significant differences between plots planted with non-NeoST maize and plots planted with NeoST maize. Specifically, in Table 1 we first report GE trait adoption rates, separately for plots that did not use NeoST and those that did. As noted earlier, there is a positive correlation between adoption of GE traits and NeoST. Table 1 also contains the fraction of plots treated with the four main insecticide alternatives to neonicotinoids, separately for non-NeoST and NeoST plots. The latter exhibit significantly lower use of pyrethroids, organophosphates, and phenylpyrazoles. Finally, Table 1 also reports the average risk quotient for 
each of the four taxa considered here. Plots planted with NeoST maize appear to have significantly lower toxicity for mammals, fish, birds, and even bees.

These patterns persist if we also account for the use of seeds embedding the genetically engineered RW trait, the most significant potential confounder in terms of contributing to the downward insecticide trends depicted in Figure 1 and Figure 2. In Table 2 we report the fraction of plots that received applications of pyrethroids and organophosphates for four groups of plots, depending on whether or not they were treated with a NeoST and/or planted with seed embedding the RW trait. It is apparent that the share of plots that received treatments with these two insecticides is significantly higher for RW seed without NeoST compared to RW seed with NeoST (e.g., 0.15 vs. 0.04 for organophosphates). Similarly, for seed without the RW trait, NeoST maize is associated with significant reductions in the use of pyrethroids and organophosphates, roughly to the same degree as when RW is present.

Table 2. Insecticide Applications by Seed Type, 2003-2014

\begin{tabular}{ccccc}
\hline \hline \multicolumn{2}{c}{-- Seed Attribute--- } & \multicolumn{3}{c}{----Insecticide---- } \\
\hline NeoST & RW & Pyrethroid $^{a}$ & Organophosphate $^{\mathrm{b}}$ & $\mathrm{N}$ \\
\hline 0 & 0 & 0.17 & 0.14 & 42,325 \\
1 & 0 & 0.12 & 0.05 & 44,881 \\
0 & 1 & 0.18 & 0.15 & 522 \\
1 & 1 & 0.11 & 0.04 & 42,302 \\
\hline
\end{tabular}

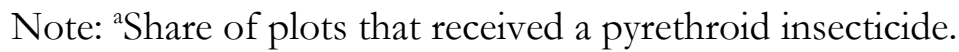
bhare of plots that received an organophosphate insecticide.

The trends and summary statistics presented in the foregoing, however, do not account for farmer heterogeneity and other possible confounding factors. To control for such effects, we exploit the panel structure of the data. Specifically, in the next section, to identify the impact of NeoST maize adoption on the use of other major foliar and soil applied insecticides, we estimate linear probability models using plot-level observations on actual insecticide choices by a large and representative sample of U.S. farmers. In so doing, we also estimate the insecticide impacts of adopting insect-resistant GE maize varieties. 


\section{Empirical Framework}

To identify the impacts of NeoST adoptoin on insecticide use we employ a fixed effects regression framework in which the unit of observation is a plot. On each plot, a farmer plants maize seed, which may or may not include a NeoST and insect-resistant GE traits. The impacts of those observed attributes on the use of organophosphates, pyrethroids, carbamates, and the various toxicity indices are estimated with the following regression equation:

$$
y_{i}=\alpha N e o S T_{i}+\beta C B_{i}+\gamma R W_{i}+\lambda_{t[i]}+\theta_{f[i]}+e_{i}, \quad i=1,2, \ldots, N
$$

where $i$ indexes the plot, $t[i]$ identifies the year in which data for plot $i$ are observed, and $f[i]$ indicates the farmer to whom the plot belongs (the notation follows Gelman and Hill (2007)). The dependent variable $y_{i}$ takes on two different forms. In the linear probability models, $y_{i}$ is an indicator variable for the use of the insecticide group of interest (organophosphates, pyrethroids, carbamates, phenylpyrazoles, and category I insecticides). In the toxicity models, $y_{i}$ is the hazard quotient $\left(H Q_{i}\right)$ computed for each of four different taxa: rats, birds, bees, and fish. The variables $N e o S T_{i}, C B_{i}$, and $R W_{i}$ are indicator variables for the presence or absence of a NeoST, the CB trait, and the RW trait, respectively. As previously noted, the inclusion of the GE trait variables, particularly the RW trait variable, is critical for estimating the NeoST impacts because the diffusion of NeoSTs and RW traits occurred around the same time and both traits are active on corn rootworms. The estimated regression models also include farmer fixed effects $\left(\theta_{f[i]}\right)$ and year fixed effects $\left(\lambda_{t[i]}\right)$. Farmer fixed effects allow for unobserved farm-level heterogeneity to be correlated with NeoST and GE trait adoption. Time fixed effects control for unobserved year-to-year confounders that do not vary over space.

\subsection{Identification}

Given the empirical objectives of this paper, it is helpful to provide a brief discussion of the sources of identification for the NeoST impacts, as well as potential limitations to our identification strategy. Most of the identifying variation comes from the rapid adoption of NeoST maize that occurred during the 2004-2008 sub-period. During this time, NeoST adoption increased from $0 \%$ to nearly $80 \%$. With data on insecticide use decisions for six years prior to the introduction of NeoST maize (1998-2003), we thus observe a large number of data points in which a particular farmer switched from not planting to planting NeoST maize. Given the inclusion of farmer and time fixed effects, the main coefficient 
of interest, $\alpha$, is thus essentially identified by comparison of the change in insecticide use by NeoST adopters to the change in insecticide use by non-adopters. We can also see from Table 1 that most of the identifying variation comes from the difference in insecticide use between plots with non-RW seed without a NeoST and plots with non-RW seed with a NeoST.

As previously discussed, a limitation to our empirical approach is the presence of unobserved confounders. Having included GE insect-resistant trait variables, farmer fixed effects, and time fixed effects, we interpret the main coefficient of interest, $\alpha$, as a reasonable estimate of the average causal impact of NeoST adoption on the respective insecticide use measures. If anything, there are reasons to believe that our results are conservative estimates of the insecticide reducing effect of NeoSTs. As noted in the context of GE trait adoption (Kniss 2017), using the pesticide usage patterns of nonadopters to infer the impacts of adoption will generate biased impact estimates if non-adopters experience significantly lower pest densities. To make this matter more concrete, denote expected pest pressure on plot $i$ by $R_{i}$. Assuming that farmers are more likely to use insecticides the higher they expect pest pressure to be, then:

$$
\begin{aligned}
& \operatorname{corr}\left(\operatorname{NeoST}_{i}, R_{i}\right) \geq 0 \\
& \operatorname{corr}\left(y_{i}, R_{i}\right) \geq 0
\end{aligned}
$$

This correlation will lead to an estimated coefficient that is "too large" (i.e., it will be biased towards indicating complementarity with both the likelihood of using an insecticide and the respective hazard quotient). Stated more plainly, if such heterogeneity is present then our estimates will understate the degree to which NeoSTs have reduced organophosphates, pyrethroids, as well as mammal, fish, and bird toxicity exposure, and overstate the degree to which they have increased bee toxicity exposure.

\section{Results}

We first report the estimation results for equation (4) where the left-hand-side variable is an indicator variable equal to one if the plot was treated with one of the five insecticide groups of interest. This is followed by the results for equation (4) where the left-hand-side is the plot-level hazard quotient, separately for each of the four taxa of interest. Basic statistics for all model variables are provided in Table A5 in the Appendix. 


\subsection{NeoST Probability Impacts on Insecticide Use}

The baseline probability impact results are reported in Table 3. The estimated coefficients indicate that the use of NeoSTs in maize is associated with a statistically significant reduction in the probability of spraying of about 7.8 percentage points for pyrethroids, 6.7 percentage points for organophosphates, and 0.6 percentage points for phenylpyrazoles. No significant impact was found for carbamates. To put these numbers in context, we also report the fraction of non-NeoST plots that used each of these insecticides during the post-NeoST era (2004-2014). For example, about 17\% of non-NeoST plots received a pyrethroid application and about 13\% received an organophosphate application. Relative to non-NeoST plots, the estimated NeoST reductions are about $47 \%$ in

Table 3. NeoST and GE Trait Probability Impacts on Use of Alternative Insecticides

\begin{tabular}{lccccc}
\hline Variable & Pyrethroids & $\begin{array}{c}\text { Organo- } \\
\text { phosphates }\end{array}$ & $\begin{array}{c}\text { Phenyl- } \\
\text { pyrazoles }\end{array}$ & Carbamates & $\begin{array}{c}\text { Category I } \\
\text { Insecticides }\end{array}$ \\
\hline NeoST & $-0.078^{* * *}$ & $-0.067^{* * *}$ & $-0.006^{* * *}$ & 0.001 & $-0.060^{* * *}$ \\
& $(0.010)$ & $(0.006)$ & $(0.001)$ & $(0.002)$ & $(0.009)$ \\
CB & $-0.016^{* * *}$ & $-0.010^{* * *}$ & -0.001 & -0.001 & $-0.014^{* * *}$ \\
& $(0.005)$ & $(0.003)$ & $(0.001)$ & $(0.001)$ & $(0.004)$ \\
RW & $-0.036^{* * *}$ & $-0.020^{* * *}$ & -0.001 & 0.000 & $-0.044^{* * *}$ \\
& $(0.010)$ & $(0.006)$ & $(0.001)$ & $(0.001)$ & $(0.010)$ \\
\hline Non-NeoST Mean ${ }^{\dagger}$ & 0.167 & 0.129 & 0.014 & 0.004 & 0.131 \\
$N$ & 182,307 & 182,307 & 182,307 & 182,307 & 182,307 \\
$R^{2}$ & 0.573 & 0.556 & 0.602 & 0.483 & 0.578 \\
\hline
\end{tabular}

Note: The estimated coefficients are based on linear probability models. The dependent variable for the insecticide group in each column is an indicator variable equal to one if the insecticide was applied to the plot. The independent variables-NeoST, CB, and RW-are indicator variables that equal one if the planted variety contained these attributes. The estimated coefficients are percentage point impacts of NeoST, CB, and RW traits on each of the insecticide variables. Standard errors, clustered at the CRD level, are reported in parentheses. ${ }^{* * *} p<0.01 ;{ }^{* *} p<0.05$. All models include year fixed effects and farmer fixed effects. ${ }^{\dagger}$ Share of plots with non-NeoST seed that were treated with the respective insecticide during the post-NeoST period (2004-2014). 
pyrethroids, 52\% in organophosphates, and 43\% in phenylpyrazoles. NeoST adoption was also associated with a 6 percentage point reduction $(46 \%)$ in the likelihood of using a category I insecticide-insecticides with an LD50 less than 50 and deemed by the EPA to be extremely hazardous to humans.

It is important to emphasize that the estimated effects of NeoSTs in Table $\mathbf{3}$ are realized even having controlled for the presence of insect-resistant GE traits, which are themselves associated with a statistically significant lower probability of using pyrethroids and organophosphates. For example, the combined impact of $\mathrm{Bt}$ traits was a 5.2 percentage point reduction in pyrethroids, a 3 percentage point reduction in organophosphates, and a 5.8 percentage point reduction in category I insecticides. Thus, when compared to the NeoST impact estimates, these results imply that the widespread adoption of NeoSTs contributed more to a reduction in conventional insecticide use than Bt traits embedded in GE varieties.

\subsection{NeoST Impacts on Species Hazard Quotients}

Overall, the foregoing estimated effects imply large substitution effects—a ban would certainly result in shifts towards conventional insecticides. What remains unclear are the implications of such shifts in terms of net environmental impact. To gain insights into this question, we next consider the estimation of equation (4) where the left-hand-side variable is the plot-level hazard quotient. The results are reported in Table 4 . We find that NeoSTs are associated with significant reductions in acute risk exposure for mammals, birds, and fish, but an increase in risk exposure for bees. Relative to mean values for non-NeoST seed, these reductions are about $49 \%$ for mammals and $48 \%$ for fish, whereas for bees the increase associated with NeoSTs is about 40\%. All estimated effects (except for birds) are statistically significant at the 1\% level. The results in Table 4 also indicate that adoption of insect-resistant GE traits is associated with a decrease in risk exposure for all four groups (and these effects are statistically significant, except for birds).

These results confirm what was suggested by the hazard quotient trends reported in Figure 2neonicotinoids generally reduce acute risk exposure for certain species (despite the fact that they are ubiquitous). How one should value these contrasting risk effects is, of course, an unanswered question, and one that remains outside of the scope this paper. But, at the very least, these results suggest that there are important tradeoffs that need to be carefully considered if neonicotinoid restrictions are to be put into place. 
Table 4. NeoST and Corn GE Trait Impacts on Acute Toxicity in Mammals, Fish, Birds, and Bees

\begin{tabular}{lcccc}
\hline Variable & Mammals & Fish & Birds & Honeybees \\
\hline NeoST & $-3.076^{* * *}$ & $-2.341^{* * *}$ & -0.638 & $374.352^{* * *}$ \\
& $(0.783)$ & $(0.326)$ & $(1.339)$ & $(54.088)$ \\
CB & & & \\
& $-1.069^{* * *}$ & $-0.639^{* * *}$ & -0.666 & $-86.662^{* * *}$ \\
& $(0.283)$ & $(0.152)$ & $(0.421)$ & $(28.801)$ \\
RW & & & \\
& $-1.170^{* *}$ & $-1.002^{* * *}$ & -0.264 & $-136.989^{* * *}$ \\
\hline Non-NeoST Mean & $(0.535)$ & $(0.293)$ & $(0.369)$ & $(41.266)$ \\
$N$ & 6.43 & 4.83 & 4.47 & 943.14 \\
$R^{2}$ & 182,307 & 182,307 & 182,307 & 182,307 \\
\hline
\end{tabular}

Note: The estimated coefficients are based on linear regression models. The dependent variable for the species groups in each column is the computed respective hazard quotient. The independent variables-NeoST, CB, and RW - are indicator variables that equal one if the seed planted on the plot contained these attributes. The estimated coefficients thus quantify the impacts of NeoST, CB, and RW traits on each of the hazard quotients. Standard errors, clustered at the CRD level, are reported in parentheses. ${ }^{* * *} p<0.01 ;{ }^{* *} p<0.05$. All models include year fixed effects and farmer fixed effects. ${ }^{\dagger}$ Average value of hazard quotient on plots with non-NeoST seed during the post-NeoST period (20042014).

\subsection{GE Trait Impacts}

Although not the primary focus of this study, the insecticide and overall toxicity impacts of the adoption of GE varieties with insect-resistant traits are of interest in their own right. To our knowledge, no previous study has estimated the farm-level impact of GE trait adoption on the use of specific insecticide groups, nor the implied impact on overall acute toxicity. Nor has any study estimated the impact of GE traits on insecticide use while controlling for NeoST adoption. The estimates in Table 3 and Table 4 indicate that GE traits have significantly reduced insecticide use and overall acute toxicity load. CB varieties are associated with a 1.6 percentage point $(9.6 \%)$ reduction in pyrethroid applications, a 1 percentage point (7.7\%) reduction in organophosphate applications, and a 1.4 percentage point $(10.7 \%)$ reduction in category I insecticides. RW varieties reduced the use of these insecticides even further, by about 3.6 percentage points $(21.6 \%)$ for pyrethroids, 2 percentage points $(15.5 \%)$ for organophosphates, and 4.4 percentage points $(33.5 \%)$ for category I insecticides. 
No significant estimated impacts are found for phenylpyrazoles or carbamates. Adoption of GE varieties that embed CB and RW resistance traits also significantly reduced the hazard quotients in mammals and fish, and, in contrast to NeoSTs, also reduced the hazard quotients for bees. In all cases, the reducing effect of RW resistance exceeded the reducing effect of CB resistance, typically by around $50 \%$.

\subsection{Policy Implications: NeoST Ban in U.S. Maize}

Neonicotinoids are currently banned in the EU, and there have been recent calls to restrict their use in the United States (Goulson 2018). Some U.S. states have already banned neonicotinoids for nonagricultural uses and several other states have proposed legislation to limit their use. To assess the impacts of a ban on NeoSTs in U.S. maize production, we use the estimated coefficients from Table 3 and Table 4 to predict the effects of a ban for the most recent year in our sample (2014). Specifically, for each field that was planted with NeoST maize in 2014, we recode the NeoST indicator variable with a zero and then use the model to predict changes in insecticide use and acute toxicity. The results of this counterfactual exercise are presented in Table $\mathbf{5}$.

Table 5. Predicted Impacts of a NeoST Ban: Insecticide Use and Hazard Quotients in 2014

\begin{tabular}{lccc}
\hline & $\begin{array}{c}\text { Observed } \\
\text { Value }\end{array}$ & $\begin{array}{c}\text { NeoST Ban } \\
\text { Predicted Value }\end{array}$ & Change (\%) \\
\hline Organophosphate Adoption $^{\dagger}$ & 0.04 & 0.10 & $174.7 \%$ \\
Pyrethroid Adoption $^{\dagger}$ & 0.13 & 0.21 & $54.9 \%$ \\
Category I Insecticide Adoption $^{\dagger}$ & 0.05 & 0.11 & $106.9 \%$ \\
Rat Hazard Quotient $^{\S}$ & 2.87 & 5.78 & $101.5 \%$ \\
Bird Hazard Quotient $^{\S}$ & 1.02 & 1.62 & $59.3 \%$ \\
Bee Hazard Quotient $^{\S}$ & 1866 & 1512 & $-19.0 \%$ \\
Fish Hazard Quotient $^{\S}$ & 4.15 & 6.37 & $53.3 \%$ \\
\hline
\end{tabular}

Note: ${ }^{\dagger}$ Percent of maize planted area. The predicted values are based on the estimated coefficients in Table 4 and Table 5

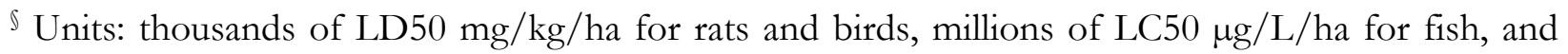
millions of LD50 $\mu \mathrm{g} / \mathrm{bee} / \mathrm{ha}$ for bees. 
Organophosphate and pyrethroid applications are predicted to increase by about 175\% and 55\%, respectively, as a consequence of such a ban. Hazard quotients are predicted to increase by about $102 \%$ for mammals, $53 \%$ for fish, and $59 \%$ for birds. The bee hazard quotient is predicted to decrease by $19 \%$. Thus, banning NeoSTs would significantly reduce acute bee exposure, but this would come at the cost of significant increases in acute toxicity exposure for mammals, fish, and birds.

\section{Discussion and Conclusion}

The control of insect pests has historically played an important role in U.S. maize production. Organochlorine insecticides such as DDT were commercially introduced for maize production in the 1950s. Subsequent years saw carbamate, organophosphate, and pyrethroid insecticides gradually replace organochlorines, with insecticide use reaching a high of $45 \%$ of planted maize acres in the mid-1980s (Osteen and Fernandez-Cornejo 2013). Neonicotinoids are among the most recent generation of agricultural insecticides and were initially lauded for their low dosage rates and positive environmental properties. Since 2001, the EPA has recommended neonicotinoids as a safer alternative to organophosphates (Hurley and Mitchell 2017).

U.S. maize farmers rapidly adopted NeoST maize, and neonicotinoids are now the most widely used insecticide in the world. But despite certain desirable properties, and notwithstanding their commercial success with farmers, declining bee populations have led to neonicotinoids coming under increasing scrutiny. The concerns raised are certainly justifiable. The global pollination industry has suffered estimated losses of more than $\$ 100$ billion in recent years (Bauer and Wing 2016), and neonicotinoids have been linked to losses in several non-pollinator organisms. But most of existing research has focused singularly on the negative consequences of neonicotinoid use, without considering the bigger picture of realized impacts from widespread NeoST adoption. In particular, there is little evidence on whether and how adoption of neonicotinoids alters the composition of insecticides used, and on how such changing insect control practices impact different organisms. Lack of data has been the primary impediment to research on these issues. If future policy regarding neonicotinoids is to be designed intelligently, answers to these questions are of major importance.

Using large-scale survey data, this study shows that the widespread adoption of NeoSTs has significantly changed the patterns of insecticide use in U.S. maize production. Adopters of NeoSTs are significantly less likely to use organophosphate and pyrethroid insecticides, and fields planted with NeoST maize exhibit, on average, significantly lower acute toxicity exposure for mammals and fish. 
Moreover, while NeoSTs are associated with increased acute exposure for honeybees, as of 2014 the average level of exposure for bees was roughly the same or just a bit higher compared to years that preceded the release of NeoSTs. Previous research has acknowledged that NeoSTs may replace older insecticides, but some have argued that having $90 \%$ of maize acres treated with NeoSTs is considerably worse than having 35\% of acres treated with older insecticides (Tooker, Douglas, and Krupke 2017). This reasoning ignores the major differences in toxicity and application rates between neonicotinoids and older insecticides. Indeed, our findings indicate that when these factors are accounted for, many organism groups may be put at greater risk by a return to a world without NeoSTs.

Our findings imply that policymakers face an important tradeoff. Regulation to limit or ban the use of neonicotinoids would likely cause U.S. farmers to substitute into organophosphate and pyrethroid insecticides, thereby increasing toxicity exposure to mammals, fish, birds, and applicators. Therefore, ex ante cost-benefit analyses of neonicotinoid restrictions should weigh the benefits of reduced toxicity exposure for pollinators against the increased exposure for other taxa, including humans.

Unintended consequences from NeoST restrictions have already been documented in the EU. Several case studies have shown that EU farmers increased the use of alternative soil and foliar applied insecticides, particularly pyrethroids, when neonicotinoids were not permitted (Kathage et al. 2018). Similar impacts have been documented for oilseed rape production in England, and other adverse effects were also observed: insect damage increased, insecticide resistance increased, yields decreased, and less oilseed rape was grown. Our findings broadly validate the recent studies in Europe. Indeed, the breadth of the data employed in this study supports the likelihood of sizeable undesirable unintended consequences from a possible U.S. ban on neonicotinoids. Thus, the analysis of this study suggests that, if new regulatory restrictions on NeoSTs are deemed necessary, then the policy design needs to account for, and possibly forestall, farmers' likely substitution into more hazardous insecticides (particularly organophosphates).

Researchers have also criticized the use of NeoST crops on the grounds that they violate basic tenets of integrated pest management (Tooker, Douglas, and Krupke 2017). Much of this criticism has centered on the repeated pre-emptive use of NeoSTs without regard to an economic threshold. These are valid criticisms, of course, particularly as they concern the development of insect resistance. Evolution of insect resistance to both insecticides and Bt traits have been major ongoing concerns (Gassmann et al. 2014; Tabashnik, Brevault, and Carriere 2013). Insofar as NeoSTs suppress pests, as 
well as reduce the use of other insecticides, it is desirable to preserve their viability. Additional measures to forestall the development of resistance may therefore be warranted. Non-Bt maize refuges have successfully delayed resistance to Bt crops, suggesting similar methods may be useful for neonicotinoids.

This study has focused on the impact of NeoST adoption on overall insecticide use in U.S. maize. Although maize accounts for the majority of NeoST applications in U.S. agriculture, neonicotinoids are now also applied on at least $40 \%$ of U.S. soybean acreage, and are widely used in the production of a variety of other crops, fruits, and vegetables. Insecticide use in soybeans, in particular, only became common beginning around 2004 with the emergence of the soybean aphid, Aphis glycines, an insect pest native to Asia that was first observed in North America in 2000 (Douglas and Tooker 2015). Because soybean farmers arguably have fewer options for the control of this pest, the findings we have documented for U.S. maize may not apply to soybeans. Moreover, whereas yield benefits from NeoST have been documented in maize (e.g., Wilde et al. 2004; Alford and Krupke 2018), evidence of yield benefits in soybeans has been more mixed and debated (Myers and Hill 2014; Hurley and Mitchell 2017). From a policy standpoint, this suggests that the costs and benefits of NeoSTs should be evaluated on a crop-by-crop basis.

Some other potentially important impacts associated with NeoST adoption were not considered in this paper. For example, several studies have shown that the widespread adoption of Bt crops confers benefits to non-Bt users by suppressing pest populations (Hutchison et al. 2010). One potentially important consideration absent from these studies is that NeoST adoption may also have contributed to area-wide suppression of various insects (Alford and Krupke 2018). In fact, the econometric results presented in this study indicate that in certain cases the insecticide reducing impact of NeoST adoption exceeded the combined effects of CB and RW trait adoption. Further work is needed to disentangle the area-wide suppression impacts of Bt traits and NeoSTs. Two additional issues that also warrant further investigation are whether there have been realized yield effects of NeoST crops, similar to the case of maize GE traits (Xu et al. 2013), and a quantification of the additional economic surplus obtained by farmers and pesticide firms from the availability of NeoSTs. 


\section{References}

Alford, A.M. and Krupke, C.H., 2018. A Meta-analysis and Economic Evaluation of Neonicotinoid Seed Treatments and Other Prophylactic Insecticides in Indiana Maize From 2000-2015 With IPM Recommendations. Journal of Economic Entomology, 111(2), pp.689-699.

Bass, C., Denholm, I., Williamson, M.S. and Nauen, R., 2015. The global status of insect resistance to neonicotinoid insecticides. Pesticide Biochemistry and Physiology, 121, pp.78-87.

Bauer, D.M. and Wing, I.S., 2016. The macroeconomic cost of catastrophic pollinator declines. Ecological Economics, 126, pp.1-13.

Battaglin, W.A., Sandstrom, M.W., Kuivila, K.M., Kolpin, D.W. and Meyer, M.T., 2011. Occurrence of azoxystrobin, propiconazole, and selected other fungicides in US streams, 2005-2006. Water, Air, \& Soil Pollution, 218(1-4), pp.307-322.

Coupe, R.H. and Capel, P.D., 2016. Trends in pesticide use on soybean, corn and cotton since the introduction of major genetically modified crops in the United States. Pest Management Science, 72(5), pp.1013-1022.

Cox, W.J., Shields, E., Cherney, D.J.R. and Cherney, J.H., 2007. Seed-applied insecticides inconsistently affect corn forage in continuous corn. Agronomy Journal, 99(6), pp.1640-1644.

Dewar, A.M., 2017. The adverse impact of the neonicotinoid seed treatment ban on crop protection in oilseed rape in the United Kingdom. Pest Management Science, 73(7), pp.1305-1309.

Douglas, M. R., \& Tooker, J. F. (2015). Large-scale deployment of seed treatments has driven rapid increase in use of neonicotinoid insecticides and preemptive pest management in US field crops. Environmental Science \& Technology, $49(8)$, 5088-5097.

Douglas, M.R. and Tooker, J.F., 2016. Meta-analysis reveals that seed-applied neonicotinoids and pyrethroids have similar negative effects on abundance of arthropod natural enemies. PeerJ, 4, p.e2776.

EPA. (undated) "Technical Overview of Ecological Risk Assessment: Risk Characterization." Accessed September 11, 2018 at https://www.epa.gov/pesticide-science-and-assessing-pesticiderisks/technical-overview-ecological-risk-assessment-risk

Feder, G. and Regev, U., 1975. Biological interactions and environmental effects in the economics of pest control. Journal of Environmental Economics and Management, 2(2), pp.75-91.

Fernandez-Cornejo, J., and S. Wechsler. 2012. Revisiting the Impact of Bt Corn Adoption by U.S. Farmers. Agricultural and Resource Economics Review 41 (3): 377-90.

Fox, G., and A. Weersink. 1995. Damage Control and Increasing Returns. American Journal of Agricultural Economics (77) 1: 33-9.

Furlan, L. and Kreutzweiser, D., 2015. Alternatives to neonicotinoid insecticides for pest control: case studies in agriculture and forestry. Environmental Science and Pollution Research, 22(1), pp.135-147.

Gangwal, S., Reif, D.M., Mosher, S., Egeghy, P.P., Wambaugh, J.F., Judson, R.S. and Hubal, E.A.C., 2012. Incorporating exposure information into the toxicological prioritization index decision support framework. Science of the total environment, 435, pp.316-325. 
Gassmann, A.J., Petzold-Maxwell, J.L., Clifton, E.H., Dunbar, M.W., Hoffmann, A.M., Ingber, D.A. and Keweshan, R.S., 2014. Field-evolved resistance by western corn rootworm to multiple Bacillus thuringiensis toxins in transgenic maize. Proceedings of the National Academy of Sciences, 111 (April 4), 14, 5141-5146.

Gelman, A., and J. Hill (2007). Data analysis using regression and multilevel/ hierarchical models. Cambridge, UK: Cambridge University Press.

Goulson, D., 2013. An overview of the environmental risks posed by neonicotinoid insecticides. Journal of Applied Ecology, 50(4), pp.977-987.

Goulson, D., 2018. Call to restrict neonicotinoids. Science, 360(6392), p. 973.

Henry, M. et al. (2012). A common pesticide decreases foraging success and survival in honey bees. Science, 336(6079), 348-350.

Hubbell, B.J., Marra, M.C. and Carlson, G.A., 2000. Estimating the demand for a new technology: Bt cotton and insecticide policies. American Journal of Agricultural Economics, 82(1), pp.118-132.

Hurley, T. and Mitchell, P., 2017. Value of neonicotinoid seed treatments to US soybean farmers. Pest Management Science, 73(1), pp.102-112.

Hutchison, W.D., Burkness, E.C., Mitchell, P.D., Moon, R.D., Leslie, T.W., Fleischer, S.J., Abrahamson, M., Hamilton, K.L., Steffey, K.L., Gray, M.E. and Hellmich, R.L., 2010. Areawide suppression of European corn borer with Bt maize reaps savings to non-Bt maize growers. Science, 330(6001), pp.222-225.

Jeschke, P., Nauen, R., Schindler, M., \& Elbert, A. (2011). Overview of the status and global strategy for neonicotinoids. Journal of Agricultural and Food Chemistry, 59(7), 2897-2908.

Kathage, J., Castañera, P., Alonso-Prados, J. L., Gómez-Barbero, M. and Rodríguez-Cerezo, E. (2018), The impact of restrictions on neonicotinoid and fipronil insecticides on pest management in maize, oilseed rape and sunflower in eight European Union regions. Pest Management Science 74: 8899 .

Kniss, A.R., 2017. Long-term trends in the intensity and relative toxicity of herbicide use. Nature Communications, 8 .

Klümper, W., \& Qaim, M. (2014). A meta-analysis of the impacts of genetically modified crops. PloS one, 9(11), e111629.

Lai, W., 2017. Pesticide use and health outcomes: Evidence from agricultural water pollution in China. Journal of Environmental Economics and Management, 86, pp.93-120.

Lichtenberg E, Zilberman D. The econometrics of damage control: why specification matters. American Journal of Agricultural Economics. 1986 May 1;68(2):261-73.

Mineau, P., Baril, A., Collins, B.T., Duffe, J., Joerman, G. and Luttik, R., 2001. Pesticide acute toxicity reference values for birds. Reviews of Environmental Contamination and Toxicology, 170, pp.13-74.

Mitchell, P.D., 2014. Market-level assessment of the economic benefits of atrazine in the United States. Pest Management Science, 70(11), pp.1684-1696. 
Myers, C.; Hill, E. (2014). Benefits of Neonicotinoid Seed Treatments to Soybean Production. United States Environmental Protection Agency: Washington, D.C.

Nelson, G.C. and Bullock, D.S., 2003. Simulating a relative environmental effect of glyphosateresistant soybeans. Ecological Economics, 45(2), pp.189-202.

Nowell, L.H., Norman, J.E., Moran, P.W., Martin, J.D. and Stone, W.W., 2014. Pesticide toxicity index - a tool for assessing potential toxicity of pesticide mixtures to freshwater aquatic organisms. Science of the Total Environment, 476, pp.144-157.

Osteen, C.D. and Fernandez-Cornejo, J., 2013. Economic and policy issues of US agricultural pesticide use trends. Pest Management Science, 69(9), pp.1001-1025.

Oude Lansink A, Carpentier A. Damage control productivity: An input damage abatement approach. Journal of Agricultural Economics. 2001 Sep;52(3):11-22.

Perry, E.D., F. Ciliberto, D. A. Hennessy, and G. Moschini (2016) "Genetically engineered crops and pesticide use in U.S. maize and soybeans." Science Advances 2, e1600850 (August 31).

Pimentel, D., 2005. Environmental and economic costs of the application of pesticides primarily in the United States. Environment, Development and Sustainability, 7(2), pp.229-252.

Roberts, J.R., and Reigart, J.R., 2013. Recognition and management of pesticide poisonings, sixth edition. U.S. Environmental Protection Agency, Office of Pesticide Programs.

Sanchez-Bayo, F. and Goka, K., 2014. Pesticide residues and bees-a risk assessment. PloS one, 9(4), p.e94482.

Scott, C. and Bilsborrow, P.E., 2019. The impact of the EU neonicotinoid seed-dressing ban on oilseed rape production in England. Pest Management Science, 75(1), pp.125-133.

Sexton, S.E., Lei, Z. and Zilberman, D., 2007. The economics of pesticides and pest control. International Review of Environmental and Resource Economics, 1(3), pp.271-326.

Sparks, T.C. and Nauen, R., 2015. IRAC: Mode of action classification and insecticide resistance management. Pesticide Biochemistry and Physiology, 121, pp.122-128.

Stackelberg, P.E., Barbash, J.E., Gilliom, R.J., Stone, W.W. and Wolock, D.M., 2012. Regression models for estimating concentrations of atrazine plus deethylatrazine in shallow groundwater in agricultural areas of the United States. Journal of Environmental Quality, 41(2), pp.479-494.

Stokstad, E. (2013). Pesticides under fire for risks to pollinators. Science, 340(6133), 674-676.

Thelin, G.P., and Stone, W.W., 2013, Estimation of annual agricultural pesticide use for counties of the conterminous United States, 1992-2009: U.S. Geological Survey Scientific Investigations Report 2013-5009, 54 p.

Tabashnik, B.E., Brévault, T. and Carrière, Y., 2013. Insect resistance to Bt crops: lessons from the first billion acres. Nature Biotechnology, 31(6), p.510.

Tooker, J.F., Douglas, M.R. and Krupke, C.H., 2017. Neonicotinoid seed treatments: limitations and compatibility with integrated pest management. Agricultural \& Environmental Letters, 2(1). 
USGS (U.S. Geological Survey), 2018. "Estimated annual agricultural pesticide use,” National Water Quality Assessment Project, https://water.usgs.gov/nawqa/pnsp/usage/maps/county-level/

Wechsler, S. and Smith, D., 2018. Has resistance taken root in us corn fields? Demand for insect control. American Journal of Agricultural Economics, 100(4), pp.1136-1150.

Wilde, G., Roozeboom, K., Claassen, M., Janssen, K. and Witt, M., 2004. Seed treatment for control of early-season pests of corn and its effect on yield. Journal of Agricultural and Urban Entomology, 21(2), pp.75-85.

Wilde, G., Roozeboom, K., Ahmad, A., Claassen, M., Gordon, B., Heer, W., Maddux, L., Martin, V., Evans, P., Kofoid, K., Long, J., Schlegel, A., and Witt, M. 2007. Seed treatment effects on earlyseason pests of corn and on corn growth and yield in the absence of insect pests. Journal of Agricultural and Urban Entomology, 24(4), pp.177-194.

Wilson, C. and Tisdell, C., 2001. Why farmers continue to use pesticides despite environmental, health and sustainability costs. Ecological Economics, 39(3), pp.449-462.

Xu, Z., Hennessy, D.A., Sardana, K. and Moschini, G., 2013. The realized yield effect of genetically engineered crops: US maize and soybean. Crop Science, 53(3), pp.735-745.

Zilberman, D., A. Schmitz, G. Casterline, E. Lichtenberg, and J. Siebert. 1991. The economics of pesticide use and regulation. Science 253:518-522.

Zilberman, D. and Millock, K., 1997. Financial incentives and pesticide use. Food Policy, 22(2),

pp.133-144. 


\section{APPENDIX}

\section{Part A - AgroTrak Data}

This section provides some additional information on the Agro'Trak dataset, the main source of data for the empirical analysis. These proprietary data constitute a commercial product assembled and marketed by Kynetec USA, Inc., St. Louis, MO (this product was formerly marketed by GfK Kynetec and, before that, by Doane Marketing Research-Kynetec, aka dmrkynetec). Iowa State University acquired limited access to these proprietary data via a marketing research agreement with Kynetec. Each year, Kynetec conducts surveys throughout the United States of randomly sampled farmers about decisions pertaining to seed and pesticide choices. The samples constructed for AgroTrak are representative at the CRD level. Each CRD is a multicounty area identified by the National Agricultural Statistics Service of the U.S. Department of Agriculture. Agrotrak ${ }^{\circledR}$ is the most comprehensive source for pesticide use data, and it has been used in several other studies, including Battaglin et al. (2011), Gangwal et al. (2012), Stackelberg et al. (2012), Thelin and Stone (2013), Mitchell (2014), and Perry et al. (2016). It is also the source data for the publicly available USGS pesticide use data (see page 3 of Thelin and Stone 2013).

The Agro'Trak surveys are administered by trained and experienced interviewers via computer assisted telephone interviews. For quality assurance, the interviews are recorded. Kynetec contacts surveyed farmers immediately following the application season. Farmers report prices, quantities, and application data. In the event that a particular variable cannot be recalled, Kynetec may impute that variable or contact the dealer who sold to the farmer for further details. However, certain questions must be answered for the survey to be accepted. These include crop acres, acres treated by product formulation, number of applications, and other information. Kynetec also has an acceptable range of prices and application rates for each product formulation, which are based on label rates and patterns of historical use.

Some details on the AgroTrak dateset are provided in Table A1. During the 1998-2014 study period, the AgroTrak data contained surveys on an average of 5,242 farmers per year, spanning 246 crop reporting districts across 39 states. As discussed in the manuscript, we observe multiple years for many farmers, which permits the inclusion of farmer fixed effects. However, the sample is not balanced. Each year, some farmers happen to be resampled by chance. Table A2 contains the distribution of 
sampled years. About $48 \%$ of these farmers were surveyed just once, $20 \%$ were surveyed twice, $11 \%$ were surveyed three times, and so on. Just fifteen farmers were surveyed for all seventeen years. Nonetheless, a substantial number of farmers were surveyed multiple years (over 10,000 were surveyed for at least three years).

Table A1. Kynetec data (AgroTrak), average values per year over the period 1998-2014

\begin{tabular}{ll}
\hline & Count \\
\hline No. of states represented & 39 \\
No. of CRDs represented & 246 \\
No. of corn farmers per year & 5,242 \\
\hline
\end{tabular}

Table A2. Distribution of years sampled, 1998-2014

\begin{tabular}{lcc}
\hline Years in Sample & $\begin{array}{c}\text { No. of } \\
\text { Farmers }\end{array}$ & Percent \\
\hline 1 & 17,032 & 48.12 \\
2 & 7,184 & 20.3 \\
3 & 3,801 & 10.74 \\
4 & 2,343 & 6.62 \\
5 & 1,475 & 4.17 \\
6 & 1,007 & 2.84 \\
7 & 763 & 2.16 \\
8 & 481 & 1.36 \\
9 & 406 & 1.15 \\
10 & 267 & 0.75 \\
11 & 208 & 0.59 \\
12 & 154 & 0.44 \\
13 & 120 & 0.34 \\
14 & 75 & 0.21 \\
15 & 44 & 0.12 \\
16 & 22 & 0.06 \\
17 & 15 & 0.04 \\
\hline
\end{tabular}




\section{Part B - LD50 and Insecticide Application Rate Data}

The LD50 values used to compute taxa-specific harzard quotients are presented in Table A3. For most chemicals, there were multiple reported values either with respect to a single organism (e.g., rats) or with respect to a group (for example, in the category "birds," values were often reported for both the bobwhite quail and the mallard duck). Thus, with the exception of the honeybee values, we use the median of reported values for each organism group. In certain cases, the reported LD50 values were lower bounds rather than observed values. For example, the LD50 value for etoxazole is " $>5,000 "$. For these cases, we use the lower bound as the value for computing the hazard quotient, which may lead to a small amount of bias. If anything, this will likely produce conservative estimates for the impact of neonicotinoids on the hazard quotient because for both rats and fish, some neonicotinoid chemicals had no observed lethal dose. Information on the sources of LD50 values is provided in the table, as well as the material and methods section of the manuscript.

Table A4 contains mean application rates (kg/ha per treatment) for each observed active ingredient in U.S. maize during the 1998-2014 study period. These values can be used in combination with the LD50 table to compute the risk quotient for an active ingredient from a typical application. For example, carbofuran has an average application rate of $0.887 \mathrm{~kg} / \mathrm{ha}$, which is equivalent to 887,000 $\mathrm{mg} / \mathrm{ha}$. Dividing by the rat LD50 of $5 \mathrm{mg} / \mathrm{kg}$, gives a risk quotient of 177,400 units (note that the units are in thousands in the manuscript). By contrast, the risk quotient for clothianidin is 40,000 $\mathrm{mg} / \mathrm{kg}$ divided by $5,000 \mathrm{mg} / \mathrm{kg}$, or just 8 units. It is important to keep in mind that these values are best viewed as imperfect proxies for risk exposure. A number of variables not considered in this study (e.g., application method and leaching potential) will impact how much of each applied chemical actually comes into contact with an organism. 
Table A3. Acute LD50/LC50 Values for Rats, Honey Bees, Fish, and Birds

\begin{tabular}{|c|c|c|c|c|c|}
\hline \multirow[b]{2}{*}{ Active Ingredient } & \multirow[b]{2}{*}{ Chemical Subgroup } & \multicolumn{3}{|c|}{ Honey } & \multirow[b]{2}{*}{$\operatorname{Bird}^{\mathrm{D}}$} \\
\hline & & $\mathrm{Rat}^{\mathrm{A}}$ & $\mathrm{Bee}^{\mathrm{B}}$ & Fish $^{\mathrm{C}}$ & \\
\hline Acephate & Organophosphates & 906 & 1.8 & 796000 & 146 \\
\hline Alpha-Cypermethrin & Pyrethroids & 239.5 & 0.044 & 1.865 & $>2000$ \\
\hline Bifenthrin & Pyrethroids & 214.8 & 0.015 & 3.2 & 1975 \\
\hline Carbaryl & Carbamates & 230 & 0.84 & 3470 & 1870.5 \\
\hline Carbofuran & Carbamates & 5 & 0.16 & 530 & 1.65 \\
\hline Chlorantraniliprole & Diamides & $>5000$ & 4 & 2160 & 2250 \\
\hline Chlorethoxyfos & Organophosphates & 3.3 & 0.09 & 45.65 & 28 \\
\hline Chlorpyrifos & Organophosphates & 182 & 0.072 & 108 & 27.36 \\
\hline Clothianidin & Neonicotinoids & $>5000$ & 0.039 & $>104200$ & 1211.5 \\
\hline Cyfluthrin & Pyrethroids & 634 & 0.019 & 0.87 & $>2000$ \\
\hline Cyhalothrin-Gamma & Pyrethroids & $>2500$ & 0.008 & 1.115 & $>2000$ \\
\hline Cyhalothrin-Lambda & Pyrethroids & 76.5 & 0.048 & 3.42 & 3950 \\
\hline Cypermethrin & Pyrethroids & 1232.3 & 0.034 & 4.7 & $>10000$ \\
\hline Deltamethrin & Pyrethroids & 62.1 & 0.024 & 1.86 & 1000 \\
\hline Diazinon & Organophosphates & 532.5 & 0.38 & 2985 & 5.25 \\
\hline Dimethoate & Organophosphates & 402.6 & 0.12 & 7150 & 29.5 \\
\hline Disulfoton & Organophosphates & 5.8 & 3.7 & 2600 & 11.9 \\
\hline Esfenvalerate & Pyrethroids & 206.5 & 0.026 & 0.25 & 1478.51 \\
\hline Ethoprophos & Organophosphates & 47 & 4.8 & 2070 & 36.8 \\
\hline Etoxazole & Etoxazole & $>5000$ & $>200$ & 2800 & $>2000$ \\
\hline Fenpyroximate & Meti Acaricides And Insecticides & 421.3 & 11 & 1 & $>2000$ \\
\hline Fipronil & Phenylpyrazoles & 97.5 & 0.007 & 83 & 39.19 \\
\hline Flubendiamide & Diamides & $>2000$ & 200 & 73.95 & $>2000$ \\
\hline Fonofos & Organophosphates & 15.2 & 5.99 & 28.5 & 23.5 \\
\hline Hexythiazox & Hexythiazox & $>5000$ & $>200$ & 530 & 3620.27 \\
\hline Imidacloprid & Neonicotinoids & 439.8 & 0.061 & 229100 & 35.36 \\
\hline Lindane & Cyclodiene Organochlorines & 85 & 0.66 & 90 & 90.83 \\
\hline Malathion & Organophosphates & 1672.2 & 0.47 & 778.7 & 466.5 \\
\hline Methomyl & Carbamates & 30 & 0.49 & 1220 & 23.69 \\
\hline Methyl Parathion & Organophosphates & 19 & 2.7 & 5220 & 10.81 \\
\hline Permethrin & Pyrethroids & 1133.3 & 0.063 & 6 & 9868 \\
\hline Phorate & Organophosphates & 2.05 & 6 & 19 & 7.06 \\
\hline Propargite & Propargite & 2413.2 & 62 & 155 & 4640 \\
\hline Spiromesifen & Tetronic And Tetramic Acid & $>2250$ & $>200$ & 16 & $>2000$ \\
\hline Tebupirimphos & Organophosphates & 2.4 & 0.32 & 48.35 & 20.3 \\
\hline Tefluthrin & Pyrethroids & 28.5 & 0.28 & 3.8 & 734 \\
\hline Terbufos & Organophosphates & 4.3 & 4.1 & 9.8 & 9.48 \\
\hline Thiamethoxam & Neonicotinoids & 1563 & 0.025 & $>107000$ & 1552 \\
\hline Zeta-Cypermethrin & Pyrethroids & 234 & 0.002 & 1.01 & 4640 \\
\hline
\end{tabular}


Footnotes to Table A3:

${ }^{\text {A }}$ Actue oral LD50 (mg/kg). Source: median of values from the Toxnet HSDB database. For chemicals not reported, we used the median of values reported on the Extension Toxicology Network (EXTOXNET).

${ }^{B}$ Acute contact LD50 ( $\left.\mu \mathrm{g} / \mathrm{bee}\right)$. Source: reported values in Sanchez-Bayo and Goka (2014).

$\left.{ }^{\text {C } A c u t e ~ e x p o s u r e ~ L C 50 ~(~} \mu \mathrm{g} / \mathrm{L}\right)$. Source: Median fish values from Nowell et al. (2014).

D Actue oral LD50 (mg/kg). Source: Median values from Mineau et al. (2001). For chemicals not reported, we used the median of values from the Toxnet HSDB database. 
Table A4. Mean Application Rates in U.S. Maize (kg per treated hectare), 1998-2014

\begin{tabular}{|c|c|c|}
\hline Active Ingredient & Chemical Subgroup & $\begin{array}{c}\text { Application } \\
\text { Rate }^{\S}\end{array}$ \\
\hline Acephate & Organophosphates & 0.383 \\
\hline Alpha-Cypermethrin & Pyrethroids & 0.022 \\
\hline Bifenthrin & Pyrethroids & 0.071 \\
\hline Carbaryl & Carbamates & 1.024 \\
\hline Carbofuran & Carbamates & 0.877 \\
\hline Chlorantraniliprole & Diamides & 0.058 \\
\hline Chlorethoxyfos & Organophosphates & 0.180 \\
\hline Chlorpyrifos & Organophosphates & 1.122 \\
\hline Clothianidin & Neonicotinoids & 0.040 \\
\hline Cyfluthrin & Pyrethroids & 0.009 \\
\hline Cyhalothrin-Gamma & Pyrethroids & 0.013 \\
\hline Cyhalothrin-Lambda & Pyrethroids & 0.025 \\
\hline Cypermethrin & Pyrethroids & 0.049 \\
\hline Deltamethrin & Pyrethroids & 0.017 \\
\hline Diazinon & Organophosphates & 0.031 \\
\hline Dimethoate & Organophosphates & 0.414 \\
\hline Disulfoton & Organophosphates & 1.277 \\
\hline Esfenvalerate & Pyrethroids & 0.031 \\
\hline Etoxazole & Etoxazole & 0.101 \\
\hline Fenpyroximate & Meti Acaricides And Insecticides & 0.112 \\
\hline Fipronil & Phenylpyrazoles & 0.117 \\
\hline Flubendiamide & Diamides & 0.066 \\
\hline Fonofos & Organophosphates & 1.014 \\
\hline Hexythiazox & Hexythiazox & 0.113 \\
\hline Imidacloprid & Neonicotinoids & 0.057 \\
\hline Lindane & Cyclodiene Organochlorines & 0.012 \\
\hline Malathion & Organophosphates & 0.861 \\
\hline Methomyl & Carbamates & 0.364 \\
\hline Methoxychlor & Methoxychlor & 0.896 \\
\hline Methyl Parathion & Organophosphates & 0.502 \\
\hline Permethrin & Pyrethroids & 0.098 \\
\hline Phorate & Organophosphates & 1.191 \\
\hline Propargite & Propargite & 2.021 \\
\hline Spiromesifen & Tetronic And Tetramic Acid Derivatives & 0.130 \\
\hline Tebupirimphos & Organophosphates & 0.141 \\
\hline Tefluthrin & Pyrethroids & 0.137 \\
\hline Terbufos & Organophosphates & 1.144 \\
\hline Thiamethoxam & Neonicotinoids & 0.014 \\
\hline Zeta-Cypermethrin & Pyrethroids & 0.019 \\
\hline
\end{tabular}

${ }^{\S}$ Computed from AgroTrak Kynetec data. 
Part C - Additional Descriptive Data

Table A5. Summary Statistics for Model Variables

\begin{tabular}{lcccc}
\hline Variable & Mean & Std. Dev. & Min & Max \\
\hline NeoST $^{\dagger}$ & 0.478 & 0.500 & 0.000 & 1.000 \\
$\mathrm{CB}^{\dagger}$ & 0.448 & 0.497 & 0.000 & 1.000 \\
$\mathrm{RW}^{\dagger}$ & 0.235 & 0.424 & 0.000 & 1.000 \\
Pyrethroid $^{\dagger}$ & 0.137 & 0.344 & 0.000 & 1.000 \\
Organophosphate $^{\dagger}$ & 0.096 & 0.295 & 0.000 & 1.000 \\
Phenylpyrazole $^{\dagger}$ & 0.009 & 0.097 & 0.000 & 1.000 \\
Carbamate $^{\dagger}$ & 0.005 & 0.070 & 0.000 & 1.000 \\
Rat Hazard Quotient & 8.177 & 42.833 & 0.000 & 874.989 \\
Fish Hazard Quotient & 5.528 & 18.307 & 0.000 & 486.664 \\
Bird Hazard Quotient & 6.274 & 42.402 & 0.000 & 1361.115 \\
Bee Hazard Quotient & $1,398.2$ & $3,710.1$ & 0.000 & $58,379.1$ \\
\hline
\end{tabular}

Note: ${ }^{\dagger}$ Indicator Variable identifying the presence of the respective trait or insecticide. Mean indicates percent of observed plots with variable equal to one.

$N=182,307$

Table A6. Pests targeted by U.S. corn farmers using foliar and soil applied insecticides during the pre-NeoST period, 1998-2003 $(\mathrm{N}=18,670)$

\begin{tabular}{lc}
\hline \hline Pest Targeted & \% Applications \\
\hline Corn Rootworm & 0.59 \\
Cutworm & 0.34 \\
Grub & 0.07 \\
Maggot & 0.07 \\
Wireworm & 0.16 \\
Armyworm & 0.03 \\
ECB & 0.11 \\
Beetle & 0.04 \\
Mite & 0.03 \\
\hline
\end{tabular}

Note: more than one pest can be reported as target in any one application. 